\title{
Research on Information Technology in Machinery Industry
}

\author{
Enxian Fu \\ ${ }^{1}$ Major of Engineering, Jiaxiang Foreign Languages School Attached Chengdu No.7 Middle School, \\ Chengdu, 610000, China
}

Keywords: Information technology; machinery industry; machinery manufacturing

\begin{abstract}
With the continuous development of the economy, information technology is made in-depth penetration in various industries, which had a great change and influence on the social era. This paper discusses the application of information technology in the machinery industry, starting from the development of the machinery industry, analyzing the characteristics of the machinery manufacturing enterprises, the difficulties faced by the information industry in the machinery industry, the significant significance of the use of information technology and the methods of the information in the machinery manufacturing industry.

Manufacturing industry is one of China's economic pillar industries, especially the machinery manufacturing industry. Therefore, improving the production and management of the machinery industry level will be of great significance to China's overall economy.

With the globalization of the economy, the world's manufacturing enterprises, especially machinery manufacturing industry gradually began to transfer to China, while a large number of capital, technology, talent joining the domestic machinery manufacturing enterprises have brought opportunities and challenges, the problem which we must face is that how to keep a solid foundation and make rapid development of machinery industry in China.
\end{abstract}

\section{The development status quo of machinery manufacturing industry in domestic}

\section{Do not attach importance to business management}

Many domestic machinery manufacturing enterprises do not attach importance to business management, business management mode and management methods are not concerned about. The management model is out of date, the management effect is poor, and the management efficiency is low, which hinders the company's operating results and the enhancement of the market competitiveness. Therefore, apply the computer information technology into the modern management ideas and innovative management model to help enterprises to enhance its comprehensive ability is imperative.

\section{Technical level cannot meet the requirements}

At present, China's machinery industry in the production process, production management and production equipment are far behind the developed countries, the main reason is that the application of information technology is poor. The progress of modern science and technology is mainly manifested in the information technology; it also made a higher standard for the machinery manufacturing industry.

\section{The characteristics of the machinery manufacturing industry}

As China's product homogeneity competition continues to intensify, the machinery industry in some small and medium-sized manufacturing enterprises are facing more and more challenges. To have priority in the production of production, it must make reasonable arrangements for production, control the delivery time of the contract to ensure timely delivery. The key point in the operation process is how to convey the production information accurately to the workshop, make the overall control of the logistics situation. The product structure in enterprise is complex, the parts of product are more and more, what's more, their type, appearance, function seem similar but have 
different characteristics, which lead to the material warehouse management is also very complex. If you do not have a complete cost control system, the company is difficult to calculate the profitability of a variety of products. In addition, the labor force of the machinery industry is relatively intensive, the standard of personnel selection is also low, so the overall quality of the enterprise is low, and the company's information management awareness and computer foundation are very inadequate, many staff makes the computer training study after joining the work.

\section{The preparation of information technology}

Information management is closely related to the efficiency of enterprise management and efficiency; enterprises need to develop their own programs according to their own characteristics.Enterprise executives must attach great importance to information technology; they recognize the importance of information technology, which lead the entire enterprise onto modernization. Therefore, before making use of information technology, the company's high-level information management concept of training is very important.Enterprise information is not only related to a project, but also related to the entire machinery industry management philosophy and market development. The use of information systems provides enterprises with a management concept.The use of information systems is a process of digitizing management ideas. The use of software systems makes the new management philosophy of solidification, which can make implementation of the enterprise protection on the management concept.The use of information systems is a process of change, especially for the traditional machinery manufacturing industry. As the enterprise has been using the traditional management model, it is bound to encounter some difficulties in the course of the development. These difficulties come from the staff of the new system of cowardice. Some workers fear changes, worried that the new system will have an impact on the existing work.

\section{The information technology problems in machinery industry}

The information technology makes a slow development in machinery industry, mainly because that the management of the machinery manufacturing industry is too complicated. The main information technology challenges that machinery industry takeare as follows:

First, demand is complex.There are many production modes of machinery manufacturing. Different production models have different management models. Different management processes have different management standards. Even if the business process can be standardized, but the manufacturing demands are variety, the business process achieves standardization that is not easy.

Second, the investment ratio is low.As the profits of the machinery manufacturing industry relative to other industries is very low, there are considerable restrictions on growth, the enterprise put most of the funds into the information unrealistic.

The income of the enterprise first invests in solving the problem of survival. The information technology usually accounts for $2 \%$ of the total profit in foreign enterprise, while China's investment ratio is usually less than $1 \%$.

Three, The investment concept is error. China's enterprises in the hardware facilities and network construction investment is more important, but they ignored the software investment, companies consider that $\mathrm{t}$ spending some money on buying the hardware is intuitive, and spending corresponding money on the software is not worth it. Foreign enterprises in the software investment accounted for about 70 percent, the rest used in hardware, and China do just the opposite. China's investment concept is wrong.

Forth, do not attach importance to the service. Some companies lack knowledge of information technology. Although they spent huge sums of money to buy the software, they refused to spend money to buy services, which also caused a huge waste, while the software that they buy cannot give full play to its real value.

Fifth, the talent is lack.Talent is generally more willing to work in IT companies compared with 
the machinery manufacturing enterprises. On the one hand, they can quickly improve their professional knowledge in IT companies, on the other hand, IT companies are often paid more than the machinery manufacturing enterprises, and the working environment is better than the machinery manufacturing enterprises, which also caused the machinery manufacturing industry lack of relevant technical personnel.

Six, the management of the business leaders are lack of change determination. If you want to make the use of information technology to achieve the machinery industry manufacturing enterprise information, we must establish the determination of change. If we spend a lot of money on the information but make lost in the execution of the force, it will hinder the development of enterprise. Leadership's determination at this time is particularly important.

\section{The significance of the information technology}

Information technology improves the development of machinery industry, but also promotes the global economic development. Its significance lies in the following:

\section{Information technology promote industrialization}

The information technology make industrial production from the mechanization to the intelligent, which improve production and management system, maximize production efficiency and accelerate the national economic development. The information industry has changed the structure of the world economic system. Any country that wants to improve its economic status in the world must first develop the information industry.

\section{The information technology brings new features to economic development}

E-commerce has become the main form of business, the quality of goods is getting higher and higher, the price is getting lower and lower, the service is getting better and better, the individuality of the commodity is more obvious.

\section{The information technology contributes to social stability and development}

The information technology makes the rapid development of various enterprises, which increased employment opportunities for the community, reducing the unemployment rate. The information technology has also increased the communication between people. The information technology makes education no longer confined to the entity line, it provide more opportunities for learning, enhancing the overall quality of the people.

\section{The information technology has contributed to national defense}

The war is different from the traditional war, which is already a high-tech war; the weapons are equipped with the information technology. Information technology plays a leading role in the war.

\section{Measures of Information Technology Application in Machinery Manufacturing Industry}

\section{Strengthen the work of government departments}

The government should implement a comprehensive mechanism reform, build a long-term mechanism of information technology; the government should create an atmosphere for information technology, provide conditions to the machinery industry; and support the financial to enterprises in the information technology.

\section{Play the function of industry associations}

Industry associations should actively organize the industry activities for information exchange, set the machinery industry information monitoring system, and vigorously promote outstanding results; it also should strengthen the establishment of the machinery industry information public service platform, set the industry information technology research and development center, carry out the machinery industry information training, further enhanced the quality of professionals. 


\section{Machinery industries play their own main function}

The industry should make a correct understanding of the importance of information technology and better transform information technology; it also should increase the advanced information products and software, and attract relevant technical personnel; make the establishment of information network to improve the resilience of enterprises; The industry should make rational planning of production processes, effective organization and coordination of production, promote new technologies to enhance the overall efficiency of the machinery industry.

\section{In conclusion}

The information technology plays a guiding role in the development of China's machinery manufacturing industry. As domestic enterprises generally lack the experience of management technology, China's machinery industry has a lower level of information technology. In order to activate the development of these enterprises to promote the healthy and steady development of China's machinery industry, we should establish a sound information system, promote China's machinery industry as soon as possible with the developed countries to further promote China's economic development.

\section{References}

[1] Wang Hongbin. Analysis of Chinese machinery manufacturing industry information [J]. Heilongjiang Science and Technology Information, 2013 (14): 82.

[2] $\mathrm{Hu} \mathrm{Bo,} \mathrm{the} \mathrm{development} \mathrm{process} \mathrm{and} \mathrm{application} \mathrm{of} \mathrm{information} \mathrm{technology} \mathrm{in} \mathrm{machinery}$ manufacturing [J]. Science and Technology Information Development and Economy .2012, (10): 227.

[3] LiZhiwei, Li Zhenhu.China's machinery manufacturing industry information development process [J]. Commodities and quality. Academic observation, 2011 (3): 16 